\title{
Ein Bild sagt mehr als 1000 Worte! Ein Film erzählt die ganze Geschichte!
}

\section{A Picture is Worth a Thousand Words! A Movie Tells the Whole Story!}

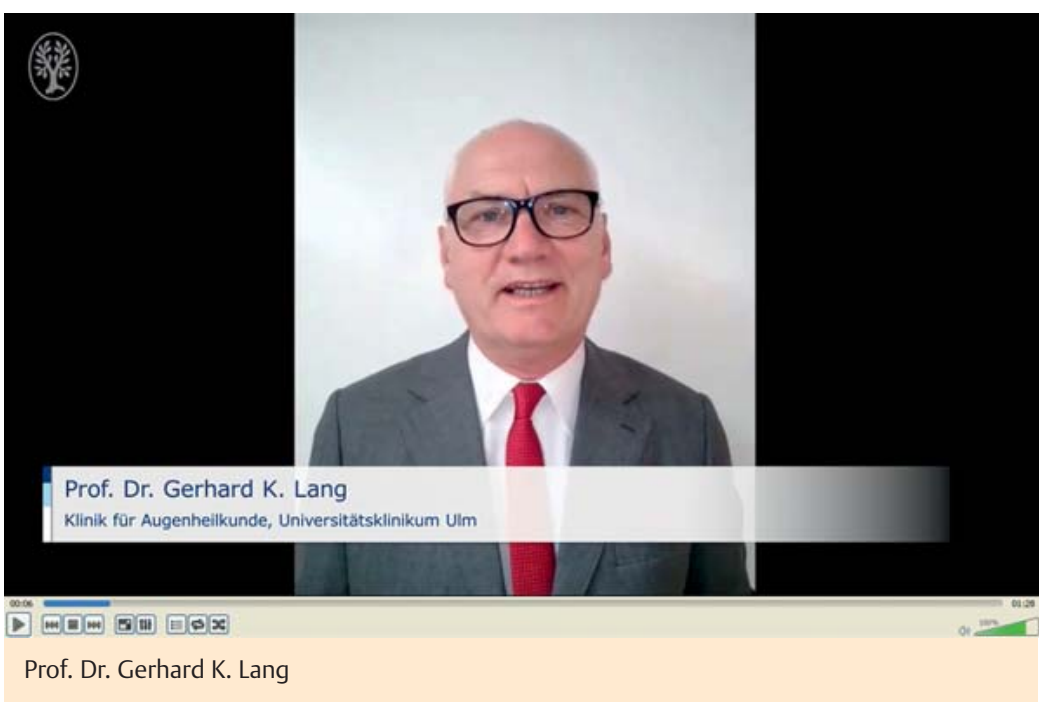

Sehr geehrte Leserinnen und Leser,

mit großer Freude möchten der Georg Thieme Verlag und die Schriftleiter der Klinischen Monatsblätter für Augenheilkunde in diesem Heft die Möglichkeit vorstellen, ab jetzt Videos zusammen mit und ergänzend zu den wissenschaftlichen Arbeiten zu veröffentlichen.

Wir haben in Zukunft für unsere Autoren die Option, neben dem geschriebenen Wort und dem illustrierenden Bild auch in Form von bewegten Bildern die gewünschten Inhalte mitzuteilen.

Über die Zeit hinweg wird sich so bei den Klinischen Monatsblättern eine hoffentlich stattliche Videothek aufbauen, auf die - genauso wie auf die Arbeiten - online zugegriffen werden kann.

„Ein Bild sagt mehr als 1000 Worte“ - ist eine Metapher für den Mehrwert von Bildern gegenüber ausschließlichem Text. Es bezieht sich darauf, dass komplizierte Sachverhalte oft mit einem Bild oder einer Darstellung sehr einfach erklärt werden können und ein Bild meist einen stärkeren Eindruck auf den Betrachter ausübt als ein umfangreicher Text. Angeblich sollen diese Worte von P.J. Reuter stammen, dem Gründer der ursprünglich deutschen Nachrichtenagentur Reuters. Diese Zuschreibung ist allerdings nicht belegt.

Und wenn ein Bild schon mehr als 1000 Worte sagt, wie viel mehr Information, aber auch Präzision und Emotion, vermittelt dann ein kurzer Film. Oder anders formuliert, wenn ein Bild schon mehr als 1000 Worte sagt, dann erzählt ein Video eine ganze Geschichte.

Der Verlag und die Herausgeber der Klinischen Monatsblätter sind sehr erfreut darüber, dass nun im 151. Jahr des Bestehens der Zeitschrift die Möglichkeit der Videoveröffentlichung gegeben ist.

Wir sehen dies als notwendigen und richtigen Schritt in einer Zeit, in der junge Wissenschaftler bereits als „Digital Natives“ aufwachsen, also Personen, die mit digitalen Technologien, wie Computern, dem Internet, Mobiltelefonen und MP3Playern großgeworden sind [1].

Aber auch die „Digital Immigrants“, die mit diesen Techniken nicht von klein auf vertraut sind, primär eine Gruppe der Geburtsjahrgänge vor 1970, wollen wir ebenfalls für diese neue Technologie begeistern und werden von Verlagsseite aus die Technik der Einreichung und auch des Abrufs so einfach wie möglich gestalten.

Mit gutem Beispiel voran und „immer einen Blick voraus" - das erste Video-Editorial der Schriftleitung können Sie online ansehen. Wir hoffen, dass Ihnen dieser Service gefällt und sind gespannt auf Ihre Rückmeldungen.

Die ersten beiden Videobeiträge der Klinischen Monatsblätter für Augenheilkunde finden Sie übrigens in dieser Ausgabe im Artikel „Ophthalmopathologie im klinischen Einsatz" ab Seite 699.

Wir freuen uns schon auf Ihre Videobeiträge!

\section{Herzlich}

Ihre Schriftleitung und das Team der Klinischen Monatsblätter für Augenheilkunde

\section{Literatur}

1 Prensky M. Digital Natives, Digital Immigrants. On The Horizon (MCB University Press) 2001; 9 (5). Im Internet: http://www.marcprensky.com/writing/ Prensky\%20-\%20Digital\%20Natives,\%20Digital\% 20Immigrants\%20-\%20Part1.pdf. Stand: 30.6.2014

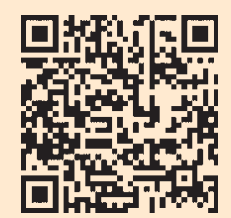

Zum Video-Editorial gelangen Sie durch Scannen des QR-Codes oder über den angegebenen Link.

Das Video zu diesem Beitrag finden Sie im Internet unter http://dx.doi.org/10.1055/s-0034-1382833 